\title{
Antenatal Emergency Department and Inpatient Use Among Massachusetts Deaf and Hard of Hearing Women: A Retrospective Cohort Study
}

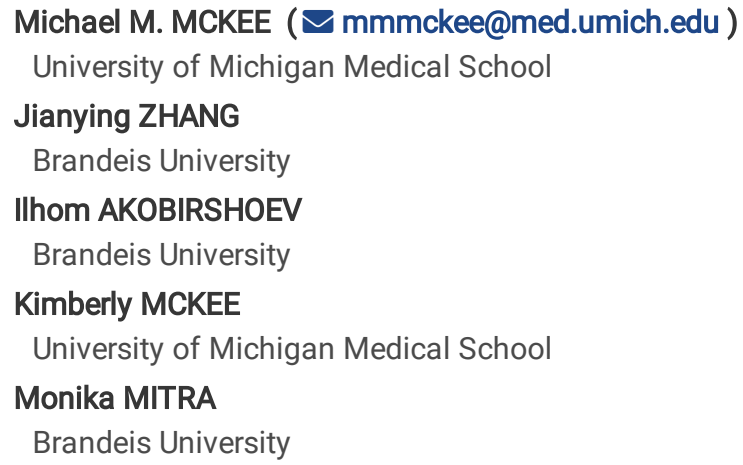

\section{Research Article}

Keywords: deaf and hard of hearing mothers, healthcare barriers, pregnant deaf mothers, deaf health

Posted Date: December 6th, 2021

DOI: https://doi.org/10.21203/rs.3.rs-1086377/v1

License: (c) (i) This work is licensed under a Creative Commons Attribution 4.0 International License. Read Full License 


\section{Abstract \\ Background}

Hearing loss is increasingly prevalent among younger adults and significantly impacts health and health care use. Deaf and hard of hearing (DHH) women have a significantly higher risk of chronic diseases, pregnancy complications and adverse birth outcomes compared to hearing women. The mechanisms, including health care utilization patterns during the perinatal period, remains not well understood.

\section{Methods}

We conducted a retrospective cohort study design to analyze 2002-2013 Massachusetts Pregnancy to Early Life Longitudinal data to compare antenatal inpatient and emergency department use between $\mathrm{DHH}(\mathrm{N}=925)$ and hearing $(\mathrm{N}=2895)$ women with singleton deliveries. Matching was done based on delivery year, age at delivery and birth parity in 1:3 case-control ratio. Demographic, socioeconomic, clinical and hospital characteristics were first compared for DHH mothers and the matched control group using chi-squared tests and t-tests. Multivariable models were adjusted for socio-demographic and clinical characteristics.

\section{Results}

Among DHH women ( $\mathrm{N}=925), 49 \%$ had at least one emergency department visit, $19 \%$ had an observational stay, and $14 \%$ had a non-delivery hospital stay compared to $26 \%, 14 \%$, and $6 \%$, respectively among hearing women $(\mathrm{N}=2895)$ during the antenatal period (all $p<0.001)$. The risk of non-delivery emergency department visits (RR 1.58; $p<0.001)$ and inpatient stays (RR 1.89; $p<0.001)$ remained higher among DHH women compared to hearing women even after adjustment for relevant variables. Having four or more emergency department visits ( $7 \%$ vs. $2 \%)$, two or more observational stays ( $7 \%$ vs. $3 \%$ ) and two or more non-delivery hospital stays ( $4 \%$ vs. $0.4 \%$ ) prior to delivery were more common among pregnant $\mathrm{DHH}$ women compared to their controls (all $\mathrm{P}<0.001$ ).

\section{Conclusion(s):}

The study findings demonstrate that DHH women during the use emergency departments and inpatient services at a significantly higher rate than their hearing controls during the antenatal period. A systematic investigation of the mechanisms for these findings, including healthcare-, patient- and provider-based factors, are needed. Health care providers should be aware of potentially heightened risk for pregnancy and birth complications among DHH women which are in part due to persistent social and healthcare barriers, including communication and language.

\section{Introduction}

Hearing loss is common, affecting approximately $15-17 \%$ of Americans, most of whom have mild to moderately severe hearing loss [1-3]. While the majority of these individuals are older, younger individuals are still at risk. Hearing loss is increasingly prevalent in younger adults, with $8.5 \%$ of individuals ages 20 to 29 years and $17 \%$ of those ages 30 to 39 years having some degree of high-frequency hearing loss [1].

Having hearing loss is associated with social isolation [4], lower socioeconomic status, including reduced income and educational attainment [5] along with impacts on psychological, cognitive and physical health [6, 7]. Additionally, deaf and hard of hearing (DHH) women have been found to be at a heightened risk for chronic conditions, pregnancy-related complications, and adverse birth outcomes [6, 7]. Little is known on why DHH women experienced higher risks for a variety of adverse events and outcomes but social and healthcare barriers, including communication and language, have been hypothesized to play a role. For example, treatment adherence, hospital readmission rates and preventive care receipts can be impacted if communication and language are not accessible [8-15]. DHH individuals also utilize emergency departments and hospitals more often $[16,17]$. DHH individuals, even those with milder forms of hearing loss have higher hospitalization rates ( $16 \%$ and $21 \%$ higher, respectively for mild and moderate hearing loss) when compared to their hearing peers [18]. DHH generate $\$ 22,000$ greater health care costs over 10 years in respect to those who are hearing, even after adjusting for health and sociodemographic factors [16, 17]. DHH individuals are also at higher risk for readmission, in part due to communication challenges. A retrospective analysis of the 20102013 Medicare Current Beneficiary Survey found that older DHH patients who had "trouble communicating" with clinicians [8] had $32 \%$ greater readmissions rate compared to their peers.

An emerging body of literature suggests that DHH women are at risk for pregnancy complications and adverse birth outcomes $[6,7,19]$. Two recent studies by Mitra and colleagues using national and state-level data found that DHH women were significantly more likely than their hearing peers to have preterm birth and low birth weight infants, and at increased risk of chronic medical conditions and pregnancy complications, including pre-existing and gestational diabetes, pre-eclampsia and eclampsia, and placental abruption [7, 19]. Deliveries to DHH 
women were significantly associated with pre-term birth and low and very low birth weight infants, and infants with low Apgar scores [7]. There is a lack of data, however, on the antenatal health care utilization patterns and risk factors among DHH women. The paper's objective is to examine differences in antenatal emergency department and inpatient utilization, and the primary indication for the utilization, among $\mathrm{DH}$ and non-DHH women.

\section{Materials And Methods Study setting}

We conducted a population-based retrospective matched case-control study in Massachusetts. Our study included all hospital-based deliveries in Massachusetts that occurred during the 2003-2013 period. The study was approved and deemed exempt under exemption category 4 by the Brandeis University IRB, protocol number 17135R-E. The original approval was issued on June 22, 2017. It was considered exempt under Category 4 of the federal regulations since the study involves analysis of secondary data and the research was conducted in a manner that the resulting dataset does not include identifiable information. Additionally, as per guidance with the use of PELL data user agreement, we did not display any frequencies less than 12 to further ensure confidentiality. All ethical guidelines according to the Declarations of Helsinki were otherwise followed.

\section{Data}

We used the Pregnancy to Early Life Longitudinal (PELL) data system, a longitudinal, population-based, reproductive health data set. PELL data links to all Massachusetts birth certificates, fetal death reports, and delivery and non-delivery (inpatient visits, observational stays, and emergency department visits) related hospital discharge records for all infants and their mothers [20, 21]. The PELL data set includes $>100$ clinical and nonclinical data elements for each delivery, including primary and secondary diagnoses and procedures. This rich dataset allows for the ability to examine both delivery and non-delivery health care use patterns, including emergency department (ED) visits, observationaland hospital-based stays. Detailed information on the design of the PELL data set is available elsewhere [7, 21-23].

\section{Study Cohort}

The PELL data include unique decoded patient identifiers; thus, the unit of analysis is any delivery to Massachusetts women who gave birth between January 1, 2002 and December 31, 2013. This time period allowed us to include all antenatal visits for women who delivered in 2003 and had antenatal visits during 2002. Additionally, we restricted deliveries to women with at least 720 days gap between two consecutives deliveries to avoid the complexity of the time overlapping between the postpartum period from one delivery and antenatal period from a subsequent delivery. Deliveries to $\mathrm{DHH}$ women $(n=925)$ or case subjects were identified by analyzing the primary and secondary diagnoses of any hospital admissions (not just those associated with deliveries), ED visit, or observational stay up to the time of delivery [7]. If any of the DHH-related diagnoses from the International Classification of Diseases and Related Health Problems 9th Revision (ICD-9 CM) codes (389.0, 389.1, 389.2, 389.7, 389.8, and 389.9) were present on the hospital discharge record, the woman was considered to have DHH [7]. The control group with no record of $\mathrm{DHH}$ status $(n=2,895)$ similar to previous research [24] was matched on delivery year, age at delivery and birth parity in $1: 3$ case-control ratio.

\section{Measures}

Dependent variables. The main dependent variables were 1) any ED visit, and 2) any hospitalization (an in-patient stay and/or observational stay). Observational stays were aggregated with inpatient stays due to their relatively low frequency in the target population. Any hospitalizations and ED visits during the antenatal period were identified in the PELL data set using linked birth certificate, inpatient discharge, outpatient observation, and ED data. The antenatal period was calculated from the beginning of pregnancy (defined as the week of gestation at birth/fetal death subtracted from the date of birth/fetal death) through the date of birth/fetal death. The primary reasons for antenatal hospital admission and ED visits were classified based on the 18 condition categories of the Clinical Classification Software (CCS) [25].

Covariates. Model covariates included maternal sociodemographic and clinical characteristics. Maternal socio-demographic characteristics at the time of delivery were derived from the birth certificate and included maternal age $(<20,20-29,30-39,40+$ years), race/ethnicity (non-Hispanic White, non-Hispanic Black, Hispanic, non-Hispanic Other), language (English, other, unknown), education (<high school, high school, some or more college), marital status (single or married), health insurance (private or public), and father named on the birth certificate (yes/no) [26]. Clinical characteristics were also derived from the birth certificate and included smoking during pregnancy and Adequacy of Prenatal Care Utilization (APNCU) Index [27]. APNCU or Kotelchuck index was categorized as: adequate plus - received 110\% of expected visits; adequate 80-109\%; intermediate - 50-79\%; and inadequate $-<50 \%$ of expected visits [27]. Diabetes during pregnancy-including both gestational and chronic-and hypertension during pregnancy (yes/no)-including both pregnancy-related and chronic (yes/no) were also obtained from birth certificate data [28]. 


\section{Analysis}

Demographic, socioeconomic, clinical and hospital characteristics were compared for DHH mothers and the matched control group. Differences across categorical variables and continuous variables between the two clinical populations were evaluated using chi-squared tests and t-tests, respectively.

We used Generalized Estimating Equations (GEEs) to estimate the unadjusted and adjusted relative risk for hospital utilization and ED visits between DHH women and the matched control group. The unadjusted and adjusted risk ratio (RR) for selected medical conditions for hospital utilization and ED visits between DHH women and the matched control group were estimated. We used GEEs to account for repeated measurements (multiple deliveries to the same woman). Primary reasons for antenatal hospital admission and ED visits, based on CCS [25] were assessed and compared between $\mathrm{DHH}$ and non-DHH mothers. We used RR or odds ratio (OR) for different measures because when an outcome is common ( $>10 \%$ in the unexposed group), the OR will exaggerate the RR [29]. Unadjusted models were adjusted for delivery year, age at delivery and birth parity because the case-control matching was based on delivery year, age at delivery and birth parity. Multivariable models were adjusted for socio-demographic (maternal age, education, race/ethnicity, marital status, health insurance, and father named on the birth certificate) and clinical characteristics (smoking, Kotelchuck index, chronic diabetes and chronic hypertension). A p-value of <0.05 was considered significant. All analyses were performed using statistical software SAS, version 9.3 (SAS Institute Inc., Cary NC). This study was approved by the authors' respective institutional review boards.

\section{Results}

\section{Maternal Characteristics}

A description of the sample comparing $\mathrm{DHH}$ women with the matched control group are presented in Table 1. Compared to the matched control group, $\mathrm{DHH}$ women were more likely to be non-Hispanic Black or Hispanic $(p<0.001)$ and more likely to communicate in other or unknown languages (e.g. American Sign Language) ( $p=0.004)$, and less likely to be married $(p<0.001)$ (Table 1). They were also more likely to have a lower education level $(p<0.001)$, more likely to receive public health insurance $(p<0.001)$, and more likely to receive "adequate plus" prenatal care based on the Kotelchuck index $(p<0.001)$ (Table 1). DHH women were also more likely to have smoked during pregnancy $(p=0.003)$ and have gestational diabetes and hypertension (all $p=0.003)$, along with chronic diabetes $(0.003)$ and hypertension $(p=0.011)($ Table 1$)$.

Table 1: Maternal Characteristics, by Deaf and Hard of Hearing (DHH) Status, 2002-2013 Massachusetts Pregnancy to Early Life Longitudinal Data System 


\begin{tabular}{|c|c|c|c|c|c|c|}
\hline Characteristics & $\mathrm{DHH}$ & & NonD & & & \\
\hline & $\mathrm{N}$ & 925 & $\mathrm{~N}$ & 2,895 & test statistic & \\
\hline & $\mathrm{n}$ & $\%$ & $\mathrm{n}$ & $\%$ & $x^{2}$ & P-value \\
\hline Age & & & & & 0.14 & 0.986 \\
\hline age $<20$ & 54 & 5.84 & 168 & 5.80 & & \\
\hline $20<=$ age $<30$ & 420 & 45.41 & 1,332 & 46.01 & & \\
\hline $30<=$ age $<40$ & 402 & 43.46 & 1,248 & 43.11 & & \\
\hline age $>=40$ & 49 & 5.30 & 147 & 5.08 & & \\
\hline Education & & & & & 14.37 & 0.001 \\
\hline Less than high school & 341 & 36.94 & 1,005 & 34.86 & & \\
\hline High school graduate & 221 & 23.94 & 562 & 19.49 & & \\
\hline Some or more college & 361 & 39.11 & 1,316 & 45.65 & & \\
\hline Maternal Race/Ethnicity & & & & & 18.17 & $<0.001$ \\
\hline Hispanic & 164 & 17.73 & 447 & 15.44 & & \\
\hline Non-Hispanic white & 624 & 67.46 & 1,950 & 67.36 & & \\
\hline Non-Hispanic black & 95 & 10.27 & 254 & 8.77 & & \\
\hline Other & 42 & 4.54 & 244 & 8.43 & & \\
\hline Language & & & & & 11.27 & 0.004 \\
\hline English & 569 & 61.51 & 1,903 & 65.73 & & \\
\hline Others & 111 & 12.00 & 246 & 8.50 & & \\
\hline Unknown & 245 & 26.49 & 746 & 25.77 & & \\
\hline Marital Status (\%Married) & 463 & 50.16 & 1,810 & 62.83 & 46.61 & $<.0001$ \\
\hline Public Health Insurance & 345 & 50.74 & 831 & 38.72 & 30.67 & $<.0001$ \\
\hline \multicolumn{7}{|l|}{ Other Characteristics } \\
\hline Father named on birth certificate & 802 & 90.21 & 2,595 & 91.50 & 1.40 & 0.237 \\
\hline Smoking during pregnancy & 102 & 14.25 & 225 & 10.18 & 9.00 & 0.003 \\
\hline Prenatal care 1th trimester & 724 & 79.74 & 2,243 & 79.79 & 0.00 & 0.970 \\
\hline \multicolumn{7}{|l|}{ Prenatal care utilization index } \\
\hline Missing & 28 & 3.03 & 109 & 3.77 & 19.54 & $<0.001$ \\
\hline Inadequate & 87 & 9.41 & 253 & 8.74 & & \\
\hline Intermediate & 68 & 7.35 & 181 & 6.25 & & \\
\hline Adequate & 335 & 36.22 & 1,265 & 43.70 & & \\
\hline Adequate Plus & 407 & 44.00 & 1,087 & 37.55 & & \\
\hline \multicolumn{7}{|l|}{ Pregnancy complications } \\
\hline Gestational Diabetes & 17 & 1.84 & 21 & 0.73 & 8.81 & 0.003 \\
\hline Gestational Hypertension & 47 & 5.08 & 87 & 3.01 & 8.93 & 0.003 \\
\hline Other pregnancy complications & 592 & 64.00 & 1,598 & 55.20 & 22.20 & $<.0001$ \\
\hline \multicolumn{7}{|l|}{ Emergency department visit } \\
\hline Any, n (\%) & 453 & 48.97 & 743 & 25.66 & 177.08 & $<.0001$ \\
\hline
\end{tabular}

Distribution of visits 


\begin{tabular}{|c|c|c|c|c|c|c|}
\hline 0 & 472 & 51.03 & 2152 & 74.34 & 202.60 & $<.0001$ \\
\hline 1 & 224 & 24.22 & 432 & 14.92 & & \\
\hline $2-3$ & 160 & 17.30 & 255 & 8.81 & & \\
\hline $4+$ & 69 & 7.46 & 56 & 1.93 & & \\
\hline \multicolumn{7}{|c|}{ Observational stay } \\
\hline Any, n (\%) & 180 & 19.46 & 350 & 12.09 & 31.86 & $<.0001$ \\
\hline \multicolumn{7}{|c|}{ Distribution of visits } \\
\hline 0 & 745 & 80.54 & 2545 & 87.91 & 41.73 & $<.0001$ \\
\hline 1 & 114 & 12.32 & 263 & 9.08 & & \\
\hline $2+$ & 66 & 7.14 & 87 & 3.01 & & \\
\hline \multicolumn{7}{|c|}{ Non-delivery Inpatient stay } \\
\hline Any, n (\%) & 129 & 13.95 & 182 & 6.29 & 54.99 & $<.0001$ \\
\hline \multicolumn{7}{|c|}{ Distribution of visits } \\
\hline 0 & 796 & 86.05 & 2713 & 93.71 & 85.94 & $<.0001$ \\
\hline 1 & 95 & 10.27 & 170 & 5.87 & & \\
\hline $2+$ & 34 & 3.68 & 12 & 0.41 & & \\
\hline \multicolumn{7}{|c|}{ Length of stay } \\
\hline Average & 5.92 & 14.61 & 3.23 & 4.54 & $t=-2.34$ & 0.02 \\
\hline Median & 3 & & 2 & & $Z=3.459$ & $<0.001$ \\
\hline
\end{tabular}

Source: Pregnancy to Early Life Longitudinal (PELL) Data, 2002-2013

Abbreviations: DHH-Deaf or hard of hearing.

\section{Antenatal ED visits}

Table 2 presents unadjusted and adjusted RR for ED and non-delivery hospital visits. After adjusting for socio-demographic, and clinical characteristics, $\mathrm{DHH}$ women had a $58 \%$ higher risk of having an ED visit during pregnancy ( $\mathrm{RR}=1.58 ; 95 \% \mathrm{Cl}, 1.44,1.73) \mathrm{compared}$ to non-DHH women. Likewise, the $\mathrm{DHH}$ women experienced an $89 \%$ higher risk of non-delivery based inpatient stays (RR=1.89; $95 \% \mathrm{Cl}, 1.58,2.27)$ compared to their non-DHH peers. DHH women also had significantly longer duration of hospital stays in terms of average days during hospitalizations (5.92 days vs $3.23 ; p=0.044)$.

Table 2: Emergency Department and Hospital Utilization by Deaf and Hard of Hearing (DHH) Status

\begin{tabular}{|c|c|c|c|c|c|c|c|}
\hline & \multirow[b]{2}{*}{$\mathrm{DHH}$} & \multirow[b]{2}{*}{ Non-DHH } & \multicolumn{2}{|c|}{ Unadjusted } & \multicolumn{2}{|c|}{ Adjusted $^{a}$} & \multirow[t]{2}{*}{ p-value } \\
\hline & & & $\mathrm{RR}$ & $95 \% \mathrm{Cl}$ & $\mathrm{RR}$ & $95 \% \mathrm{Cl}$ & \\
\hline Number of deliveries, $\mathrm{n}(\%)$ & $925(100)$ & $2,895(100)$ & & & & & \\
\hline Number ${ }^{\mathrm{a}}$ of total ED visits, $\mathrm{n}(\%)$ & $1,061(100)$ & $1,341(100)$ & & & & & \\
\hline Pregnancies with at least an ED visit, $\mathrm{n}(\%)$ & $453(48.97)$ & $743(25.66)$ & 1.92 & $1.75-2.10$ & 1.58 & $1.44-1.73$ & $<0.001$ \\
\hline Number ${ }^{\mathrm{a}}$ of total non-delivery inpatient/obs stay , $\mathrm{n}(\%)$ & $548(100)$ & $691(100)$ & & & & & \\
\hline Pregnancies with non-delivery inpatient/obs stay, $n \quad$ (\%) & $309(33.40)$ & $532(18.4)$ & 1.71 & $1.49-1.94$ & 1.89 & $1.58-2.27$ & $<0.001$ \\
\hline Length of stay (average days; SD) & $\begin{array}{l}5.92 \\
(14.61)\end{array}$ & $3.23(4.54)$ & & & & & 0.044 \\
\hline
\end{tabular}

Source: Pregnancy to Early Life Longitudinal (PELL) Data, 2002-2013 
Abbreviations: DHH-Deaf or hard of hearing.

a Adjusted model included the following covariates: maternal age (<20, 20-29, 30-39, 40+ years), race/ethnicity (non-Hispanic White, nonHispanic Back, Hispanic, non-Hispanic Other), language (English, other, unknown), education (<high school, high school, some or more college), marital status (married or married), health insurance (private or public), and father named on the birth certificate (yes/no). Clinical characteristics were also derived from the birth certificate and included smoking during pregnancy, chronic diabetes and chronic hypertension and Adequacy of Prenatal Care Utilization (APNCU) Index. APNCU or Kotelchuck index was categorized as adequate plus - received $110 \%$ of expected visits; adequate $-80-109 \%$, intermediate $-50-79 \%$, and inadequate $-<50 \%$ of expected visits.

Patterns of risk for select health condition categories among those who utilized the ED and inpatient stays during the antenatal period were also examined. The leading diagnoses categories for ED for DHH were complications of pregnancy and childbirths, and diseases of the nervous system and sense organs. For the non-DHH women, the leading diagnoses included complications of pregnancy and childbirths as the top condition, and injury and poisoning (see Table 3). The leading diagnoses categories for inpatient stays for both $\mathrm{DHH}$ and non-DHH were complications of pregnancy and childbirths, and mental illness (see Table 4).

Table 3: Top Clinical Classifications Listed by ED Visit by Deaf and Hard of Hearing (DHH) Status

\begin{tabular}{|c|c|c|c|}
\hline & Top 10 Clinical Classifications Listed by ED Visit & $\mathrm{N}$ & $\%$ \\
\hline \multirow[t]{10}{*}{$\mathrm{DHH}$} & Complications of pregnancy; childbirth; and the puerperium & 556 & 52.40 \\
\hline & Diseases of the nervous system and sense organs & 111 & 10.46 \\
\hline & Symptoms; signs; and ill-defined conditions and factors influencing health status & 67 & 6.31 \\
\hline & Diseases of the respiratory system & 65 & 6.13 \\
\hline & Injury and poisoning & 65 & 6.13 \\
\hline & Mental illness & 39 & 3.68 \\
\hline & Diseases of the digestive system & 37 & 3.49 \\
\hline & Diseases of the genitourinary system & 28 & 2.64 \\
\hline & Diseases of the musculoskeletal system and connective tissue & 26 & 2.45 \\
\hline & Diseases of the circulatory system & 17 & 1.60 \\
\hline \multirow[t]{10}{*}{ Non-DHH } & Complications of pregnancy; childbirth; and the puerperium & 775 & 57.79 \\
\hline & Injury and poisoning & 113 & 8.43 \\
\hline & Symptoms; signs; and ill-defined conditions and factors influencing health status & 97 & 7.23 \\
\hline & Diseases of the respiratory system & 87 & 6.49 \\
\hline & Diseases of the digestive system & 53 & 3.95 \\
\hline & Diseases of the genitourinary system & 50 & 3.73 \\
\hline & Diseases of the nervous system and sense organs & 49 & 3.65 \\
\hline & Diseases of the musculoskeletal system and connective tissue & 27 & 2.01 \\
\hline & Diseases of the circulatory system & 21 & 1.57 \\
\hline & Diseases of the skin and subcutaneous tissue & 21 & 1.57 \\
\hline
\end{tabular}

Source: Pregnancy to Early Life Longitudinal (PELL) Data, 2002-2013

Abbreviations: DHH-Deaf or hard of hearing.

Table 4: Top 5 Clinical Classifications by Hospital/Observational Stay by Deaf and Hard of Hearing (DHH) Status 
Top 5 CCS in Hospital/Observational room stay

\begin{tabular}{|c|c|c|c|}
\hline & & $\mathrm{N}$ & $\%$ \\
\hline \multirow[t]{5}{*}{$\mathrm{DHH}$} & Complications of pregnancy; childbirth; and the puerperium (CCS11) & 489 & 89.23 \\
\hline & Mental illness (CCS5) & 18 & 3.28 \\
\hline & Injury and poisoning (CCS16) & $<11$ & NR \\
\hline & Diseases of the respiratory system (CCS8) & $<11$ & NR \\
\hline & Diseases of the blood and blood-forming organs (CCS17) & $<11$ & NR \\
\hline \multirow[t]{5}{*}{ Non-DHH } & Complications of pregnancy; childbirth; and the puerperium (CCS11) & 659 & 95.37 \\
\hline & Mental illness (CCS5) & 12 & 1.74 \\
\hline & Injury and poisoning (CCS16) & $<11$ & NR \\
\hline & Symptoms; signs; and ill-defined conditions and factors influencing health status (CCS17) & $<11$ & NR \\
\hline & Diseases of the digestive system (CCS9) & $<11$ & NR \\
\hline
\end{tabular}

Source: Pregnancy to Early Life Longitudinal (PELL) Data, 2002-2013

Abbreviations: DHH-Deaf or hard of hearing.

Discussion

\section{Principal Findings}

This study offers the first examination of antenatal ED and hospital use among DHH women in the U.S. using population-based, longitudinally linked, administrative data. As hypothesized, DHH women were significantly more likely to experience higher rates of antenatal non-deliverybased ED and inpatient visits compared to non-DHH women. The results are consistent with multiple DHH related healthcare utilization studies among the general population of $\mathrm{DHH}$ using both claims and non-claims based $[17,18,30]$. DHH women in this study were more racially and ethnically diverse and with lower social economic status than their non-DHH matched peers. Even after controlling for prenatal care utilization, DHH women were at an increased risk for antenatal ED visits and hospital stays. Similar to what has been shown for women with other types of disabilities [26,31], the Kotelchuck index, based on the quantity and the timing of prenatal care visits, may fail to capture the adequacy of the prenatal visits for DHH women. For example, the Kotelchuck index does not account for the components, comprehensiveness, accessibility, nor quality of the prenatal care. The index likely doesn't reflect the communication needs of DHH women, and whether they were met during the prenatal care appointments, or the quality of their interaction, which may have significant effects on their compliance with treatment, health and wellbeing, and hospital use.

Breakdowns in language and healthcare communication may drive higher rates of ED use and inpatient hospital utilization. This may also reflect issues with communication accessibility and provider-patient relationship quality. DHH women in the study were less likely to report English as a native language. While it is unknown which language was primarily used, it is likely that some of these women communicated primarily in sign language. Communication accessibility unfortunately remains infrequent and inconsistent in healthcare despite the passage of the Americans with Disabilities Act over 30 years ago. One study highlighted that among Deaf signers, only $17 \%$ of their primary care appointments were attended by a sign language interpreter [32]. This resulted in both lower willingness of Deaf signers to see their primary care providers and higher rates of medication errors. In contrast, ED are viewed as a location in which obtaining a sign language interpreter is easier and more reliable [30].

Even for DHH individuals who communicate in English, communication breakdowns often occur in the hospital setting and this has resulted in higher rates of hospital and ED visits as well as associated readmissions [8]. Health care providers rarely screen patients for hearing loss and if positive, often lack training on how to effectively communicate with $\mathrm{DHH}$ patients. This is combined with the fact that $\mathrm{DHH}$ individuals are at higher risk for inadequate health literacy, including poor navigational literacy [30,33]. DHH individuals struggle with reduced fund of knowledge across a variety of health topics [30,34-38]. This knowledge gap may reduce the ability for DHH women to appropriately understand signs of false labor, complications of pregnancy and how to effectively seek care.

Health burdens, including the presence of diabetes and hypertension, along with risky behavior such as tobacco use during pregnancy, were higher among DHH women [7]. This parallels other work that demonstrated higher health burdens among older DHH adults [18,39-45]. The mechanism remains unclear. Due to the younger age of this cohort, it is less likely that hearing loss is simply secondary to metabolic and 
microvascular pathophysiology that damages the hearing apparatus. There may be other bio-behavioral factors driving the increased need for inpatient and emergency department services. For example, it is likely that a high proportion of the DHH women in this study likely have congenital or early age onset of hearing loss. The etiology of congenital hearing loss shifted largely from an infectious cause to genetic and prematurity related sequelae $[46,47]$ yet little is known how these affect their clinical correlates or phenotypes. DHH individuals also have demonstrated higher risk for tobacco and substance use disorders [48,49], possibly due to inaccessible public service announcements on the dangers of these substances, lower overall self-esteem, and higher rates of mental health disorders [49-51]. These risk factors exert powerful adverse influences on pregnancy and birth health.

There may be other drivers such as long-standing stressors and higher rates of mental health disorders that may influence their inpatient and ED use. Mental health conditions were associated with a significantly higher proportion of DHH women's ED visits in contrast to non-DHH women. Secondary analysis using the above data demonstrated that $\mathrm{DHH}$ women were 2 times more likely than their non-DHH peers to have mental health listed as a leading diagnosis for ED (OR 2.10; $95 \% \mathrm{Cl} 1.02-4.32)$. For hospital stays, this was not significant despite a similar trend (OR 2.00; 95\% Cl 0.72-5.60). DHH individuals, similar to people with other types of disabilities, experience higher rates of stress, depression, anxiety, and interpersonal violence, factors that may impact pregnancy outcomes [51-54]. These factors, along with poor mental health, significantly elevate the risk of low birth weight and preterm birth along with their need for inpatient services [55]. Additionally, DHH women were less likely to have a spouse, which can lead to reduced social and interpersonal support for them during their pregnancy [56-61].

\section{Strengths and Limitations}

To our knowledge, this is the first study of antenatal hospital utilization among DHH women. While the use of a longitudinal, linked, populationbased dataset to identify DHH women is a notable strength, several limitations remain. First, there was no process of clinical and audiometric corroboration of the DHH codes. Most health care providers default to "Hearing Loss, Not Otherwise Specified (NOS)" (nearly 76\% of women who were classified as such in the DHH sample) rather than select specific hearing loss codes. This may simply be reflective of health care providers noting the presence of the hearing loss that were sufficient to make a general diagnosis, but unsure of a specific hearing loss diagnosis, including its etiology or laterality. Coding rules specify that only diagnoses actively managed or treated (including those that affect health care delivery or communication) should be listed, it is possible that not all DHH women were identified and is likely an underestimate. Secondly, there was no way to ascertain the hearing loss severity and their communication preferences (e.g. ASL) based on the ICD-9 codes. However, multiple studies have also used similar ICD-9-CM codes to identify DHH status $[7,17,62]$. Thirdly, the dataset lacks the ability to determine the quality or how healthcare communication took place. Lastly, the dataset is representative for the women in Massachusetts, it may not be generalizable to women residing in other states.

\section{Conclusions}

The study findings demonstrate that $\mathrm{DHH}$ women during the antenatal period use the ED and inpatient services significantly more often than their hearing peers. This underscores the need for a systematic investigation of the mechanisms for this, including healthcare-, patient- and provider-based factors. The health care disparities also highlight the need to ensure effective and accessible health care communication as well as find novel ways to provide clinical support during the antenatal period for DHH women. Due to significantly higher health care use and documented risk for adverse pregnancy and birth outcomes, clinicians should closely monitor DHH women to identify addressable risk factors in an effort to help reduce their disparities. Further work is needed to help develop effective and evidence-based clinical and policy interventions to improve DHH women's pregnancy and birth outcomes as well as reduce reliance on ED and hospital services for non-delivery related causes.

\section{Abbreviations}

$\mathrm{DHH}$ : deaf and hard of hearing

ED: emergency department

CCS: Clinical Classification Software

OR: odds ratio

RR: risk ratio

GEEs: Generalized Estimating Equations

APNCU: Adequacy of Prenatal Care Utilization

ICD-9 CM: International Classification of Diseases and Related Health Problems $9^{\text {th }}$ Revision 
PELL: Pregnancy to Early Life Longitudinal

\section{Declarations}

\section{Ethics approval and consent to participate}

The study was approved and deemed exempt under exemption category 4 by the Brandeis University IRB, protocol number $17135 \mathrm{R}-\mathrm{E}$. The original approval was issued on June 22, 2017. It was considered exempt under Category 4 of the federal regulations since the study involves analysis of secondary data and the research was conducted in a manner that the resulting dataset does not include identifiable information. Additionally, as per guidance with the use of PELL data user agreement, we did not display any frequencies less than 12 to further ensure confidentiality. All ethical guidelines according to the Declarations of Helsinki were otherwise followed.

\section{Consent for publication}

Not applicable.

\section{Availability of data and materials}

The datasets used and analyzed during the current study are available from the corresponding author on reasonable request.

\section{Competing interests}

The authors declare that they have no competing interests.

\section{Funding}

Research was supported by the Eunice Kennedy Shriver National Institute of Child Health \& Human Development of the National Institutes of Health [R01HD090104]. Drs. MM and MMM are also supported by \#90DPGRE0001-05. The content is solely the responsibility of the authors and does not necessarily represent the official views of the funding agency. No other financial disclosures were reported by the authors of this paper.

\section{Authors' contributions}

MMM and MM provided the study conceptualization. MMM, MM, JZ, KM and IA analyzed and interpreted the data. MMM was a major contributor in writing the manuscript. All authors interpreted the findings and contributed to writing the manuscript, as well as reading and approving the final manuscript.

\section{Acknowledgements}

Not applicable.

\section{References}

1. Agrawal Y, Platz EA, Niparko JK. Prevalence of hearing loss and differences by demographic characteristics among US adults: data from the National Health and Nutrition Examination Survey, 1999-2004. Arch Intern Med. 2008;168(14):1522-30. doi:10.1001/archinte.168.14.1522

2. Blackwell DL, Lucas JW, Clarke TC. Summary health statistics for U.S. adults: national health interview survey, 2012. Vital Health Stat. 2014;10(260).

3. Ries PW. Prevalence and characteristics of persons with hearing trouble: United States, 1990-91. Vital Health Stat 10. 1994;(188):1-75.

4. Ciorba A, Bianchini C, Pelucchi S, Pastore A. The impact of hearing loss on the quality of life of elderly adults. Clin Interv Aging. 2012;7:15963. doi:10.2147/CIA.S26059

5. Bainbridge KE, Wallhagen MI. Hearing loss in an aging American population: extent, impact, and management. Annu Rev Public Health. 2014;35:139-52. doi:10.1146/annurev-publhealth-032013-182510

6. Mitra M, McKee MM, Akobirshoev I, Ritter GA, Valentine AM. Pregnancy and neonatal outcomes among deaf and hard of hearing women: results from nationally representative data. Womens Health Issues. 2021;31(5):470-7. doi:10.1016/j.whi.2021.03.005

7. Mitra M, McKee MM, Akobirshoev I, et al. Pregnancy, birth, and infant outcomes among women who are deaf or hard of hearing. Am J Prev Med. 2020;58(3):418-26. doi:10.1016/j.amepre.2019.10.012 
8. Chang JE, Weinstein B, Chodosh J, Blustein J. Hospital readmission risk for patients with self-reported hearing loss and communication trouble. J Am Geriatr Soc. 2018;66(11):2227-8. doi:10.1111/jgs.15545

9. DeWalt DA, Boone RS, Pignone MP. Literacy and its relationship with self-efficacy, trust, and participation in medical decision making. Am J Health Behav. 2007;31(Suppl 1):S27-35. doi:10.5555/ajhb.2007.31.supp.S27

10. Frist WH. Overcoming disparities in U.S. health care. Health Aff (Millwood). 2005;24(2):445-51. doi:10.1377/hlthaff.24.2.445

11. McKee MM, Barnett SL, Block RC, Pearson TA. Impact of communication on preventive services among deaf American Sign Language users. Am J Prev Med. 2011;41(1):75-9. doi:10.1016/j.amepre.2011.03.004

12. McKee MM, Winters PC, Fiscella K. Low education as a risk factor for undiagnosed angina. J Am Board Fam Med. 2012;25(4):416-21. doi:10.3122/jabfm.2012.04.110282

13. Mick P, Foley DM, Lin FR. Hearing loss is associated with poorer ratings of patient-physician communication and healthcare quality. J Am Geriatr Soc. 2014;62(11):2207-9. doi:10.1111/jgs.13113

14. Stewart MA. Effective physician-patient communication and health outcomes: a review. CMAJ. 1995;152(9):1423-33.

15. Torres RE. The prevading role of language on health. J Health Care Poor Underserved. 1998;9(5):S21-5. doi:10.1353/hpu.2010.0716

16. McKee MM, Winters PC, Sen A, Zazove P, Fiscella K. Emergency department utilization among Deaf American Sign Language users. Disabil Health J. 2015;8(4):573-8. doi:10.1016/j.dhjo.2015.05.004

17. Reed NS, Altan A, Deal JA, et al. Trends in health care costs and utilization associated with untreated hearing loss over 10 years. JAMA Otolaryngol Head Neck Surg. 2019;145(1):27-34. doi:10.1001/jamaoto.2018.2875

18. Genther DJ, Betz J, Pratt S, et al. Association between hearing impairment and risk of hospitalization in older adults. J Am Geriatr Soc. 2015;63(6):1146-52. doi:10.1111/jgs.13456

19. Mitra M, Akobirshoev I, McKee MM, lezzoni LI. Birth outcomes among U.S. women with hearing loss. Am J Prev Med. 2016;51(6):865-73. doi:10.1016/j.amepre.2016.08.001

20. Barfield WD, Clements KM, Lee KG, Kotelchuck M, Wilber N, Wise PH. Using linked data to assess patterns of early intervention (EI) referral among very low birth weight infants. Matern Child Health J. 2008;12(1):24-33. doi:10.1007/s10995-007-0227-y

21. Clements KM, Barfield WD, Kotelchuck M, Lee KG, Wilber N. Birth characteristics associated with early intervention referral, evaluation for eligibility, and program eligibility in the first year of life. Matern Child Health J. 2006;10(5):433-41. doi:10.1007/s10995-006-0080-4

22. Matthews M, Severin vX, Jelka Z. WHO technical consultation on postpartum and postnatal care. World Health Organization. 2008. http://apps.who.int/iris/bitstream/handle/10665/70432/WHO_MPS_10.03_eng.pdf;jsessionid=8A34450BB8942F777214DB7514C22DE1? sequence=1. Accessed 27 Sept 2016.

23. Clements KM, Mitra M, Zhang J, Parish SL. Postpartum health care among women with intellectual and developmental disabilities. Am J Prev Med. 2020;59(3):437-44. doi:10.1016/j.amepre.2020.03.011

24. Lokhandwala T, Khanna R, West-Strum D. Hospitalization burden among individuals with autism. J Autism Dev Disord. 2012;42(1):95-104. doi:10.1007/s10803-011-1217-x

25. AHRQ. Clinical Classifications Software (CSC) for ICD-9-CM. Agency for Healthcare Research and Quality (AHRQ). 2017. www.hcupus.ahrq.gov/toolssoftware/ccs/ccs.jsp. Accessed 12 Dec 2017.

26. Mitra M, Parish SL, Akobirshoev I, Rosenthal E, Moore Simas TA. Postpartum hospital utilization among Massachusetts women with intellectual and developmental disabilities: a retrospective cohort study. Matern Child Health J. 2018;22(10):1492-501. doi:10.1007/s10995-018-2546-6

27. Kotelchuck M. An evaluation of the Kessner Adequacy of Prenatal Care Index and a proposed Adequacy of Prenatal Care Utilization Index. Am J Public Health. 1994;84(9):1414-20. doi:10.2105/ajph.84.9.1414

28. Mitra M, Parish SL, Clements KM, Zhang J, Simas TAM. Antenatal hospitalization among U.S. women with intellectual and developmental disabilities: a retrospective cohort study. Am J Intellect Dev Disabil. 2018;123(5):399-411. doi:10.1352/1944-7558-123.5.399

29. Viera AJ. Odds ratios and risk ratios: what's the difference and why does it matter? South Med J. 2008;101(7):730-4. doi:10.1097/SMJ.0b013e31817a7ee4

30. McKee MM, Paasche-Orlow MK, Winters PC, et al. Assessing health literacy in Deaf American Sign Language Users. J Health Commun. 2015;20(Suppl 2):92-100. doi:10.1080/10810730.2015.1066468

31. O'Hearn A. Deaf women's experiences and satisfaction with prenatal care: a comparative study. Fam Med. 2006;38(10):712-6.

32. Alexander A, Ladd P, Powell S. Deafness might damage your health. Lancet. 2012;379(9820):979-81. doi:10.1016/S0140-6736(11)61670-X

33. Wells TS, Nickels LD, Rush SR, et al. Characteristics and health outcomes associated with hearing loss and hearing aid use among older adults. J Aging Health. 2020;32(7-8):724-34. doi:10.1177/0898264319848866 
34. Heuttel KL, Rothstein WG. HIV/AIDS knowledge and information sources among deaf and hearing college students. Am Ann Deaf. 2001;146(3):280-6. doi:10.1353/aad.2012.0067

35. Margellos-Anast H, Estarziau M, Kaufman G. Cardiovascular disease knowledge among culturally Deaf patients in Chicago. Prev Med. 2006;42(3):235-9. doi:10.1016/j.ypmed.2005.12.012

36. Tamaskar P, Malia T, Stern C, Gorenflo D, Meador H, Zazove P. Preventive attitudes and beliefs of deaf and hard-of-hearing individuals. Arch Fam Med. 2000;9(6):518-25, discussion 526. doi:10.1001/archfami.9.6.518

37. Woodroffe T, Gorenflo DW, Meador HE, Zazove P. Knowledge and attitudes about AIDS among deaf and hard of hearing persons. AIDS Care. 1998;10(3):377-86. doi:10.1080/09540129850124154

38. Zazove P, Meador HE, Reed BD, Sen A, Gorenflo DW. Cancer prevention knowledge of people with profound hearing loss. J Gen Intern Med. 2009;24(3):320-6. doi:10.1007/s11606-008-0895-3

39. Genther DJ, Frick KD, Chen D, Betz J, Lin FR. Association of hearing loss with hospitalization and burden of disease in older adults. JAMA. 2013;309(22):2322-4. doi:10.1001/jama.2013.5912

40. Lin FR, Yaffe K, Xia J, et al. Hearing loss and cognitive decline in older adults. JAMA Intern Med. 2013;173(4):293-9. doi:10.1001/jamainternmed.2013.1868

41. Livingston G, Sommerlad A, Orgeta V, et al. Dementia prevention, intervention, and care. The Lancet. 2017;390(10113):2673-734. doi:10.1016/S0140-6736(17)31363-6

42. McKee MM, Stransky ML, Reichard A. Hearing loss and associated medical conditions among individuals 65 years and older. Disabil Health J. 2018;11(1):122-5. doi:10.1016/j.dhjo.2017.05.007

43. National Council on the Aging. The consequences of untreated hearing loss in older persons. ORL Head Neck Nurs. 2000;18(1):12-6.

44. Thomson RS, Auduong P, Miller AT, Gurgel RK. Hearing loss as a risk factor for dementia: a systematic review. Laryngoscope Investig Otolaryngol. 2017;2(2):69-79. doi:10.1002/lio2.65

45. Wallhagen MI, Strawbridge WJ, Shema SJ. The relationship between hearing impairment and cognitive function: a 5-year longitudinal study. Res Gerontol Nurs. 2008;1(2):80-6. doi:10.3928/19404921-20080401-08

46. McKee M, Schlehofer D, Thew D. Ethical issues in conducting research with deaf populations. Am J Public Health. 2013;103(12):2174-8. doi:10.2105/AJPH/2013.301343

47. Zazove P, Atcherson SR, Moreland C, McKee MM. Hearing loss: diagnosis and evaluation. FP Essent 2015;434:11-7.

48. Kushalnagar P, Hoglind T, Simons AN, Guthmann D. Prevalence of alcohol use: a national survey of deaf adults in the United States. JADARA. 2019;52(2):24-32.

49. McKee MM, Meade MA, Zazove P, Stewart HJ, Jannausch ML, Ilgen MA. The relationship between hearing loss and substance use disorders among adults in the U.S. Am J Prev Med. 2019;56(4):586-90. doi:10.1016/j.amepre.2018.10.026

50. Cowgill BO, Herrmann A, Richardson J, et al. Understanding e-cigarette knowledge and use among d/Deaf and hard of hearing students and the need for tailored prevention programming: a qualitative study. Am Ann Deaf. 2020;165(3):335-52. doi:10.1353/aad.2020.0022

51. Fellinger J, Holzinger D, Pollard R. Mental health of deaf people. Lancet. 2012;379(9820):1037-44. doi:10.1016/S0140-6736(11)61143-4

52. Anderson ML, Leigh IW. Intimate partner violence against deaf female college students. Violence Against Women. 2011;17(7):822-34. doi:10.1177/1077801211412544

53. Pertz L, Plegue M, Diehl K, Zazove P, McKee M. Addressing mental health needs for deaf patients through an integrated health care model. J Deaf Stud Deaf Educ. 2018;23(3):240-8. doi:10.1093/deafed/eny002

54. Porter JL, Williams LM. Auditory status and experiences of abuse among college students. Violence Vict. 2011;26(6):788-98. doi:10.1891/0886-6708.26.6.788

55. Shah PS, Shah J, Knowledge Synthesis Group on Determinants of Preterm LBWB. Maternal exposure to domestic violence and pregnancy and birth outcomes: a systematic review and meta-analyses. J Womens Health (Larchmt). 2010;19(11):2017-31. doi:10.1089/jwh.2010.2051

56. Alio AP, Bond MJ, Padilla YC, Heidelbaugh JJ, Lu M, Parker WJ. Addressing policy barriers to paternal involvement during pregnancy. Matern Child Health J. 2011;15(4):425-30. doi:10.1007/s10995-011-0781-1

57. Alio AP, Kornosky JL, Mbah AK, Marty PJ, Salihu HM. The impact of paternal involvement on feto-infant morbidity among Whites, Blacks and Hispanics. Matern Child Health J. 2010;14(5):735-41. doi:10.1007/s10995-009-0482-1

58. Alio AP, Mbah AK, Kornosky JL, Wathington D, Marty PJ, Salihu HM. Assessing the impact of paternal involvement on racial/ethnic disparities in infant mortality rates. J Community Health. 2011;36(1):63-8. doi:10.1007/s10900-010-9280-3

59. Ghosh JK, Wilhelm MH, Dunkel-Schetter C, Lombardi CA, Ritz BR. Paternal support and preterm birth, and the moderation of effects of chronic stress: a study in Los Angeles county mothers. Arch Womens Ment Health. 2010;13(4):327-38. doi:10.1007/s00737-009-0135-9

Page $12 / 13$ 
60. Ngui E, Cortright A, Blair K. An investigation of paternity status and other factors associated with racial and ethnic disparities in birth outcomes in Milwaukee, Wisconsin. Matern Child Health J. 2009;13(4):467-78. doi:10.1007/s10995-008-0383-8

61. Padilla YC, Reichman NE. Low birthweight: Do unwed fathers help? Children and Youth Services Review: Elsevier. 2001;23(4-5):427-452. Doi: 10.1016/S0190-7409(01)00136-0

62. Mahmoudi E, Zazove P, Meade M, McKee MM. Association between hearing aid use and health care use and cost among older adults with hearing loss. JAMA Otolaryngol Head Neck Surg. 1 2018;144(6):498-505. doi:10.1001/jamaoto.2018.0273z 